\title{
AULAS DE MATEMÁTICA NOS CONTEXTOS DA EDUCAÇÃO DO CAMPO
}

\author{
MATHEMATICS IN FIELD EDUCATION CONTEXTS
}

\author{
Samya de Oliveira Lima ${ }^{1}$ \\ Marcus Bessa de Menezes²
}

\section{Resumo}

Neste trabalho, objetivou-se analisar o ensino de Matemática na modalidade da Educação do Campo. Conforme definido pela legislação brasileira, a Educação do Campo deve ser específica e emancipatória mediante as expressões sociais, culturais e políticas de cada sujeito. Discussões recentes na área da Educação do Campo apontam a importância de fomentar, nos processos de ensino e aprendizagem, o protagonismo dos educandos por meio de situações didáticas que incluam as dimensões sociais, culturais e políticas existentes nos diferentes contextos desses sujeitos. A abordagem metodológica se configurou em um estudo de caso com característica etnográfico. É pautada numa abordagem qualitativa, na perspectiva da Etnomatemática. A pesquisa foi realizada na Universidade Regional do Cariri - Urca, no Estado do Ceará, com estudantes do curso, sendo estruturada na aplicação do questionário. Espera-se que estes estudos sobre ensinar Matemática nos cursos de Licenciatura do Campo possam contribuir para uma reflexão acerca do processo de formação desses educandos. A valorização das vivências, das experiências cotidianas e dos sonhos, reconhecendo o sujeito em seu espaço, em suas raízes, sua cultura, seus conhecimentos, seus desejos, para dar "voz" e "vez" e resgatar nos discentes o seu direito à cidadania, com a finalidade de termos uma sociedade com mais oportunidades e menos desigualdades.

Palavras-chave: Ensino. Educação do Campo. Educandos. Etnomatemática. Matemática.

\section{Abstract}

This work aimed to analyze the teaching of mathematics in the field of rural education. Rural education as defined by Brazilian law must be specific and emancipatory through the social, cultural and political expressions of each subject. Recent discussions in the field of rural education

\footnotetext{
${ }^{1}$ Mestre em Ensino de Ciências e Educação Matemática pela Universidade Estadual da Paraíba. Docente da Universidade Regional do Cariri (URCA). Membro do Grupo de Pesquisa em Educação Matemática nos contextos da Educação do Campo e do Grupo de Pesquisa em Educação Matemática e Estatística da Universidade Federal do Pernambuco. - E-mail: samyasol@yahoo.com.br

${ }^{2}$ Doutor em Educação pela Universidade Federal de Pernambuco. Pós-doutor em Educação Matemática pela Universidade Federal de Pernambuco e Universidad Complutense de Madrid. Docente do Programa de Pós-Graduação em Ensino de Ciências e Educação Matemática Universidade Estadual da Paraíba.

E-mail: marcusbessa@gmail.com
} 
Aulas de Matemática nos contextos da Educação no Campo

point to the importance of fostering in the teaching and learning processes the protagonism of learners through didactic situations that include the social, cultural and political dimensions exis ting in the different contexts of these subjects. The methodological approach was a case study with ethnographic characteristics. It is taken in a qualitative approach from the perspective of ethnomathematics. The research was conducted at the Regional University of Cariri - Urca, with students of the course, being structured in three moments: participant observation, questionnaire application and semi-structured interviews. It is hoped that these studies on teaching Mathematics in the Field Degree courses can contribute to a reflection on the process of formation of these students. The valorization of the experiences, daily experiences and dreams, recognizing the subject in his space, in his roots, his culture, his knowledge, his desires, to give a "voice" and "time" and rescue in the students the their right to citizenship in order to have a society with more opportunities and less inequality.

Key words: Teaching. Field Education. Learners. Ethnomathematics. Mathematics.

\section{Introdução}

O presente estudo decorre de questionamentos dos próprios autores sobre o ensino de Matemática na perspectiva da Educação do Campo. Seja no campo ou na cidade, o modelo de ensino se caracteriza pela oralidade, escrita, lápis, ou seja, ainda prioriza a memorização, repetição de exercícios, dentre outras abordagens memorísticas que, atualmente, não correspondem às reais necessidades da sociedade.

A Educação do Campo é um processo histórico, fruto de lutas e mobilizações dos movimentos sociais do campo por condições concretas de subsistência no seu próprio espaço. Acrescentamos que a Educação do Campo, como prática dos movimentos sociais camponeses, segundo o dicionário da Educação do Campo (CALDART et al., 2012), busca conjugar a luta pelo acesso à educação pública contra a tutela política e pedagógica do Estado. 
Aulas de Matemática nos contextos da Educação no Campo

A Constituição de 1998 e a Lei de Diretrizes e Bases da Educação n. 9.394/96 muito contribuíram para novas perspectivas ao processo de construção de politicas públicas de educação direcionadas para essa modalidade. Com efeito, essas leis abriram procedentes legais, jurídicos e políticos que viabilizam uma educação que respeita a identidade do sujeito do campo.

O movimento da Educação do Campo é propiciado pela Pedagogia da Alternância, em que a aprendizagem dos educandos é mediada por momentos de estudos ao longo do Tempo Escola e Tempo Comunidade. Essa metodologia teve iniciativa por camponeses da França em 1935. Já no Brasil, a iniciativa chegou com os jesuitas. Assim, a alternância tem como objetivo garantir uma atuação pedagógica mediada pela teoria e prática, de forma a relacionar os processos de aprendizagem tanto para a aquisição de conhecimentos necessários à vida cotidiana quanto para a qualificação profissional. Trata-se de uma práxis educativa.

Nesse interim, com a Resolução CNE/CEB n 2/2008, foram instituídos a nucleação das escolas e o transporte escolar. Em 2010, a Educação do Campo foi instituída como modalidade de ensino. O artigo 28 da LDB diz: "na oferta de educação básica para a população rural, os sistemas de ensino promoveram as adaptações necessárias à sua adequação às peculiaridades da vida rural e de cada região".

No mesmo ano, através do Decreto $\mathrm{n}^{\circ}$. 7.352/2010, o Ministério da Educação dispõe sobre a política de educação de campo e o Programa Nacional de Educação na Reforma Agrária (PRONERA), no qual também ficou estabelecido o apoio técnico-financeiro para as escolas do campo. O referido decreto traz algumas políticas públicas 
Aulas de Matemática nos contextos da Educação no Campo

para a Educação do Campo que definiram a abrangência dos termos da população do campo e os limites da escola do campo.

Diante do exposto, podemos dizer que a Educação do Campo, como prática social, vem se consolidando a partir das lutas pela transformação da realidade, protagonizada pelo Movimento dos Trabalhadores Rurais Sem Terra (MST) ${ }^{3}$. Esses movimentos têm mostrado para a história que os sujeitos do campo têm direito de serem tratados como humanos e de se educarem como humanos. Assim, coloca-se a importância da tríade: campo-política pública-educação.

O nosso pressuposto é de que o ensino de Matemática, no âmbito da Educação do Campo, deve partir de uma lógica da terra, na qual os sujeitos vivem, constroem, lutam e defendem seu modus vivendi. Nessa perspectiva, o ensino de Matemática desenvolvido em sala de aula deve contemplar os modos próprios de pensar matematicamente o mundo que é vivenciado pelo sujeito do campo em suas práticas cotidianas. Isso significa dizer que, tendo uma escola efetivamente inserida na realidade do homem/mulher do campo, se incorpora em suas práticas pedagógicas atividades articuladas com o contexto sociocultural, merecendo, desta forma, a busca de meios que valorizem o espaço geográfico em que o ensino está inserido.

Diante do exposto, a Escola do Campo deve ser vista, de acordo com Arroyo, Caldart e Molina (2011, p. 111), como uma das dimensões do processo de formação de pessoas, e não como algo especialíssimo, para cuja obtenção, tudo o mais deva ser abandonado. A escola se torna um fator relevante no fortalecimento desses povos, que também são geradores de conhecimentos. Freire (2015, p. 116), em sua obra

${ }^{3}$ O MST surgiu no Brasil na década de 1980, se constituindo em um movimento de ativismo político e social e está organizado em 25 estados do país.

Matemática \& Ciência, v. 3, n. 1, p. 56-69, jun. 2020 - ISSN 2674-9416 
Aulas de Matemática nos contextos da Educação no Campo

Pedagogia do Oprimido, enfatiza que "uma educação autêntica, não se faz de A para B ou de A sobre B, mas de A com B, mediatizados pelo mundo".

Discutindo e analisando atentamente como vem se apresentando o processo de ensino de Matemática, nos contextos da Educação do Campo, percebe-se uma articulação com uma vertente denominada EtnoMatemática.

A EtnoMatemática começou a fazer parte de discussões entre pensadores e estudiosos da década de 1970. O termo foi constituído pelo professor Ubiratan D'Ambrosio. Conforme D' Ambrosio (2011), a expressão EtnoMatemática significa que há varias maneiras, técnicas, habilidades de explicar, de entender, de lidar e de conviver com distintos contextos naturais e socioeconômicos da realidade.

Assim, a partir do que foi exposto, é possivel compreender que a Matemática gerada por diferentes grupos sociais é objeto de estudo da EtnoMatemática, ou seja, estuda a Matemática produzida por diferentes grupos étnicos. Já as pesquisas dessa teoria têm dado suporte nas discussões no que tange à universalidade do conhecimento matemático, por exemplo, apontando para a existência de diferentes formas de matematizar o mundo. Vale ressaltar que essa discussão remete ao currículo escolar, pois nos deparamos, muitas vezes, com um ensino único da Matemática mergulhado em mecanismos os quais vêm proporcionando a "incapacidade cognitiva por parte dos alunos/as".

Dessa forma, a EtnoMatemática sinaliza a importância de inserir, no processo de ensino e aprendizagem da Matemática, a cultu-ra dos educandos/as e suas vivências, apontando para um currículo que inclua os saberes não hegemônicos. Isso significa dizer que trabalhar 
Aulas de Matemática nos contextos da Educação no Campo

com o contexto dos alunos não significa criar "probleminhas" inadequados, mas, problemas que abordem valores que estejam ligados aos grupos culturalmente identificados.

No entanto, é importante destacar que a EtnoMatemática pontua a necessidade de trabalhar com a Matemática acadêmica no contexto escolar. Frente às abordagens acima mencionadas, Knijnik esclarece:

A Matemática Acadêmica, a Matemática Escolar, as Matemáticas Camponesas, as Matemáticas Indígenas, em suma, as Matemáticas geradas por grupos culturais específicos podem se entendidas como conjuntos de jogos de linguagem engendrados em diferentes formas de vida, agregando critérios de racionalidades específicos. (KNIJNIK, 2012, p. 31).

Assim, as teorizações propostas por Gelsa Knijnik e por autores, como Ubiratan D' Ambrosio, buscam mostrar que a EtnoMatemática propõe uma não neutralidade para as dimensões que, na maioria das vezes, ficam às margens de nossas práticas pedagógicas.

Esta pesquisa foi destinada aos estudantes da Licenciatura em Matemática oriundos do Campo, no intuito de fomentar discussões e questionamentos sobre as dificuldades e limitações no que tange ao ensino de Matemática como fonte de fortalecimento para a Educação no Campo.

Para que fosse efetivada a pesquisa, fez-se necessário investigar o processo de ensino e aprendizagem da Matemática, no sentido de atender às especificidades da Educação do Campo. Os objetivos específicos foram: (i) realizar estudos sobre a Educação do Campo e sobre a EtnoMatemáti- 
ca, buscando melhor entendimento; (ii) identificar quais práticas e metodologias estão previstas com vistas à valorização do conhecimento advindo do contexto do aluno, pretendendo a melhoria das condições do processo de aquisição deste público específico.

Nesta ótica, a importância desse trabalho justifica-se pela necessidade de compreender como se dá o ensino da Matemática nesta modalidade, a fim de aprofundar os questionamentos e estudos na área.

\section{Metodologia}

A pesquisa realizada foi pautada numa abordagem qualitativa, que tem como principal característica a busca da compreensão dos fenômenos, na qual as informações obtidas são interpretadas e não quantificadas (OLIVEIRA, 2014, p. 25).

Foi realizado um processo de observação e participação na busca de promover a reflexão o discurso da pesquisadora e professora Samya de Oliveira Lima, no propósito de contribuir para o aperfeiçoamento da ação. Os educandos são os sujeitos da pesquisa da situação estudada, numa perspectiva de compreender, através de narrativas e relatos dos mesmos, como os educadores estão mediando o ensino da Matemática perante as peculiaridades baseadas nos princípios da Educação do Campo.

O desenvolvimento deste trabalho se configura enquanto um estudo de caso com característica de estudo etnográfico, sendo utilizadas técnicas no cumprimento dos objetivos que foram a observação participante e aplicação do questionário aos educandos do curso. $\mathrm{O}$ processo de investigação da observação participante aconteceu durante 
Aulas de Matemática nos contextos da Educação no Campo

as aulas de Matemática na Universidade Regional do Cariri, lócus dessa pesquisa.

A elaboração do questionário constou de questões abertas e fechadas no intuito de facilitar uma melhor compreensão dos mesmos. A escolha das perguntas foi direcionada ao problema proposto de maneira clara, concreta e precisa. A construção do questionário foi estabelecida em função do objetivo que se pretendia alcançar e, consequentemente, que as respostas pudessem contribuir para o esclarecimento do problema. O tipo do questionário foi formatado na Escala de Likert, que permite que o entrevistado expresse com detalhes sua opinião.

O trabalho de campo, que se efetivou com a aplicação do questionário, foi realizado na Universidade Regional do Cariri - Urca, em Crato, Ceará, no período matutino do mês de setembro de 2017. Diante dessa técnica, o questionário foi aplicado pelos pesquisadores aos oito discentes da turma de Ciências da Natureza e Matemática. No entanto, foi aplicado um questionário para cada educando.

\section{Resultados e discussões}

A observação participante e a aplicação do questionário proporcionaram uma série de reflexões acerca do profissional diante suas práticas pedagógicas relativas à didática e às metodologias a serem desenvolvidas em suas disciplinas, especificamente à matemática. Em vários momentos, afirmações refletem o entendimento de que os elementos do cotidiano rural são meios para atingir o conteúdo matemático que costuma fazer parte dos programas curriculares.

No contexto da Educação do Campo, determinados elementos disponiveis na própria comunidade, como as plantações, as construções

\footnotetext{
Matemática \& Ciência, v. 3, n. 1, p. 56-69, jun. 2020 - ISSN 2674-9416
} 
e as culturas podem servir como elementos instigadores para o processo de ensino e aprendizagem da Matemática, no qual o docente precisa incorporar nas suas aulas esses elementos. Considerando alguns relatos surgidos, apresentamos fragmentos do texto:

- como contextualizar os conteúdos matemáticos com alunos oriundos do campo?

- quais suas reais necessidades, além do conteúdo matemático?

- que referências complementares podem ajudar no planejamentos das aulas?

conclui-se que o professor que respeita os saberes dos educandos, busca caminhos para traduzir a Matemática.

O Programa de Apoio à Formação Superior em Licenciatura em Educação do Campo (Procampo) foi implantado pela Universidade Regional do Cariri com o objetivo de proporcionar formação, em nível de licenciatura, para professores em serviço que não possuem o curso superior e aqueles que atuam no campo. O curso tem a duração de quatro anos. Os licenciados têm uma missão de contribuir como mediadores do conhecimento em sua realidade, buscando a transformação social, lutando pela permanência das escolas e de políticas públicas.

A partir dos relatos, os discentes deixaram suas impressões, umas positivas, outras nem tanto, mas contribuíram de forma relevante para os pesquisadores vigorarem seu trabalho. Podem ser observadas as seguintes questões: 
Aulas de Matemática nos contextos da Educação no Campo

1. O que fez você ingressar no Curso Procampo?

2. O que motivou a Cursar Ciências da Natureza e Matemática?

3. Você pensa em atuar como Professor apenas em comunidades rurais? Sim ( ) Não ( ) - Justifique.

Seguem descritas algumas respostas sobre o motivo de os estudantes ingressarem no Curso Procampo:

"Ter minha formação"

"Primeiramente ter uma graduação e, depois, reverter à realidade do campo"

"A necessidade e a vontade de cursar uma graduação e minha ligação com o campo".

Verificamos que os alunos sonham com uma formação acadêmica e alguns pretendem consolidar sua atuação profissional na área rural.

Sobre o que os motivou a Cursar Ciências da Natureza e Matemática, aparece fortemente suas aptidões e inclinação pela área:

"Sempre quis trabalhar com essa disciplina"

"Afinidade, sempre gostei"

"Ensino essa disciplina"

"Gosto da proposta". 
Aulas de Matemática nos contextos da Educação no Campo

Referente à questão que procurava verificar se os estudantes pretendiam atuar profissionalmente somente em comunidades rurais, algumas respostas foram:

"Sim, mas só no Ensino Médio."

"Não, diante das dificuldades, quero ir para zona urbana."

"Não, quero seguir outras áreas."

"Não, pretendo atuar como palestrante com trabalhadores rurais."

Por estas declarações, identificamos que alguns discentes não têm uma motivação forte para lecionar na área rural. Uma das causas se situa nas condições pouco satisfatórias com a qual o professor se depara, muitas vezes, com falta de infraestrutura nas unidades educativas. Os desafios são muitos. Outro motivo é a intenção de se estabelecer na cidade e buscar outras oportunidades de trabalho. O desejo de atuar como palestrante, como indicou um dos alunos, tem o objetivo de uma ação político-social, visando a uma articulação comunitária e transformação social.

Protagonizada pelos movimentos sociais, a Educação do Campo, ao se consolidar como modelo científico, condiz como um dos mais importantes movimentos de transformação social via educação. O diálogo entre os movimentos sociais e a universidade vem proporcionando novas formas de se conceber a educação como forma de emancipação dos povos do campo.

Pudemos observar que, os educandos ressaltaram que o curso foi um evento vitorioso na região do Cariri por ter possibilitado viabilizar 
questões, até então, embaçadas pela indiferença e preconceito com a população do campo, além de ter colocado em evidência providências a serem tomadas pela universidade para a efetivação da sua missão social.

Nesse contexto, a proposta da Etnomatemática é interligar a disciplina com situações reais. Assim, evidenciamos o conteúdo de geometria plana, contemplando tal tendência; discutindo e analisando atentamente como vem se apresentando a Etnomatemática no ensino de matemática nos contextos da Educação do Campo.

Faz-se necessário também destacar que, os instrumentos para a coleta de dados, foram relevantes, como aporte para identificarmos as lacunas presentes nos processos de ensino e aprendizagem ocorridos no curso. A princípio, como destacamos, a formação dos docentes estava desvinculada da proposta da Educação do Campo. Essa formação produzia um ensino de abordagem mecânica, limitada, fechada, alicerçada num pensamento científico. Esses aspectos identificados serão parte de uma nova pesquisa como continuidade dos nossos estudos.

\section{Conclusões}

Diante do exposto, o trabalho em questão diz respeito às relações entre o ensino de Matemática e a Educação do Campo numa abordagem Etnomatemática, indagando o que pode fazer inferência entre a matemática usada no contexto dos campesinos e a matemática acadêmica/formal, no sentido de dialogar esses saberes que serão relevantes no processo cognitivo de cada indivíduo. 
Portanto, é importante pensar em um ensino de Matemática específico para a Educação do Campo, que seja planejado e desenvolvido para o contexto do campo, valorizando o saber informal. Nessa perspectiva, a escola é convidada a trabalhar de forma contextualizada, focando a interdisciplinaridade e a transdisciplinaridade.

O que foi discutido até aqui se encontra no âmbito de um estudo bibliográfico, contribuindo para possiveis pesquisas que abordem como ocorre o ensino de Matemática na Educação do Campo.

Esperamos que nosso estudo possa contribuir para reflexões sobre a inserção da Educação do Campo no âmbito do Ensino de Matemática, que o professor leve em consideração a realidade de cada aluno.

Podemos ratificar que a nossa pesquisa foi conduzida a partir de reflexões críticas sobre a prática docente de um dos pesquisadores, sustentadas pelo aporte teórico que corroborou o presente estudo.

\section{Referências}

ARROYO, Miguel G; CALDART, Roseli Salete; MOLINA, Mônica Castagna. Por uma educação do campo. 5. ed. Petrópolis: Vozes, 2011.

D'AMBROSIO, Ubiratan. Etnomatemática: elo entre as tradições e a modernidade. Belo Horizonte: Autêntica, 2011. 
FREIRE, Paulo. Pedagogia do oprimido. 56. ed. Rio de Janeiro: Paz e Terra, 2015.

KNIJNIK, Gelsa. Etnomatemática em movimento. Belo Horizonte: Autêntica, 2012.

OLIVEIRA, Maria Marly. Como fazer pesquisa qualitativa. 6. ed. Petrópolis: Vozes, 2014. 